\title{
Formula Alamin: ALAMTOLOGI Communication
}

\author{
Muhammad Aminullah ${ }^{1,2,3}$ \\ ${ }^{1}$ Researcher in ICNS-ALAMTOLOGI Kuala Lumpur, Malaysia \\ ${ }^{2} S 3$ Alumni Postgraduate at North Sumatra Sumetera UIN \\ ${ }^{3}$ Lecturer at Islamic Religion Institute ( IAI) Al-Aziziyah Samalangan \\ aminulullahtengku@gmail.com
}

\begin{abstract}
This study is very important as a solution to explain the proper communication and how to implement the right communication process in achieving harmony values for all elements related to humans. Unlimited communication between human relations, but also need to understand the form of relations with other than humans. The methodology used in this study is based on an approach that was awakened in the discipline of ALAMTOLOGI namely the XYZ formula. The XYZ formula explains all the life processes that are manifest are still subject to the $X Y Z$ relationship. $X$ as the executor, namely human, $Z$ as the media, namely the element of nature, and $Y$ as the creator, namely constructor $Z$ and $X$. The result of research that is harmonious communication is communication carried out by means of legal agreement, starting from process planning, process implementation to process achievement. Legal accuracy, that is, every action taken by $X$ in using $Z$, must understand the value of prosperity possessed by element $Z$. Planning the communication process can be carried out in four stages, namely the accuracy of planning, preparation of planning tools, willingness of planning tools and willingness to implement the implementation process. The right communication is to be able to produce certainty based on the certainty of the process. However, if communication is based on perceptions of the process, then it certainly produces predictions of results. This is what is called harmony communication.
\end{abstract}

Keywords: Alamin; formula; communication; alamtologi; science

\section{Introduction}

ALAMIN Formula is a form of reference for the basic formula for the development of all formulas related to XYZ communication studies that are examined in ALAMIN. Formation of formulas is one very important concept in achievement to form a theory, because the existence of formulas can be an appropriate proof of the development of the theory. The ALAMIN formula can be seen in Figure 1 below.

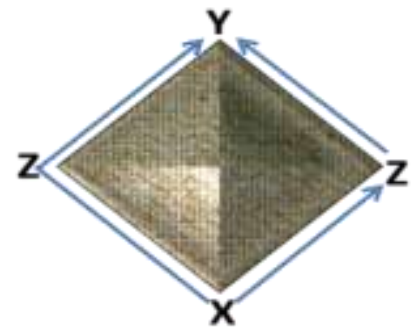

Formula

$$
X+Z(Y)
$$

Application:

1. $X$ the reference to $Z$ reaches $Y$

2. $X$ reference to $Z$ does not reach $Y$

Figure. 1: ALAMIN Formula

This formula needs to be understood that $\mathrm{XYZ}$ communication is the initial process for the formation of ALAMIN. This theory has its core point in the XYZ relationship, where the three elements have a very precise relationship. This relationship is formed either directly $\mathrm{X}$ to $\mathrm{Y}$ through space $\mathrm{Z}$, and also the relationship $\mathrm{X}$ with $\mathrm{Z}$ to reach $\mathrm{Y}$. In this position $\mathrm{Z}$ is the media in connecting $\mathrm{X}$ to $\mathrm{Y}$. Therefore, it can be understood that the relationship $\mathrm{X}$ to $\mathrm{Y}$ must go through a process in environment $\mathrm{Z}$. This needs to be understood, actually $\mathrm{Y}$ does 
not need $\mathrm{Z}$ space to reach a relationship to $\mathrm{X}$, but $\mathrm{X}$ cannot be reached with $\mathrm{Y}$ if there is no $\mathrm{Z}$ space. ${ }^{1}$

As for the explanation in the study of XYZ communication, the ALAMIN formula can be understood there are two forms of application, namely $X+Z$ (Y) and $X-Z$ (0). The application form $\mathrm{X}+\mathrm{Z}(\mathrm{Y})$ is $\mathrm{X}$ accepting to make $\mathrm{Z}$ as a media and reference in implementing $X Y Z$ communication. The acceptance is to give the value of contribution in the form of maintaining and maintaining all the elements in space $\mathrm{Z}$, so the implementation of this contribution value $X$ can be the capacity value for $X$ to connect communication in the form of a harmonious value to $\mathrm{Y}$. (0) namely $\mathrm{X}$ refuses to make $\mathrm{Z}$ as a media and reference in implementing XYZ communication.

The form of the process of applying the ALAMIN formula is based on the image above, which is to keep returning to the two forms of the process of applying the $X Y Z$ communication value in ALAMIN. The two forms of the process are $X$ legal agreement $\left(\mathrm{A}^{\mathrm{h}}\right)$ or legal $\mathrm{X}\left(\mathrm{E}^{\mathrm{h}}\right)$. The legal $\mathrm{X}-\mathrm{X}$ is a reference to $\mathrm{Z}$ to achieve a harmonious value of power to $\mathrm{Y}$. Whereas the legal $\mathrm{X}$ that is $\mathrm{X}$ refers to a reference to $\mathrm{Z}$ in the form of letting the value of capacities crippled to prosperity $\mathrm{Z}$, then the implementation of $\mathrm{X}$ to $\mathrm{Z}$ cannot reach a harmonious relationship to $\mathrm{Y}$. While the boundary value for $\mathrm{X}$ who performs the law is the emptiness of harmony value or called empty value $(0)^{2}$

Based on the ALAMIN formula, it really needs to be understood to be able to apply the communication process in daily life so that it can bring harmony values. Harmony value in communication becomes the main goal in all processes of relationships that are awakened in the form of interaction. Good interaction definitely produces a good relationship. Therefore, good communication is a universal hope for all humanity. But today's problem is how to realize good communication, and how to carry out a good communication process. The purpose of this communication base can already be established in the NATURAL Formula. Based on the ALAMIN Formula, harmonious communication is communication carried out by legal means, starting from process planning, process implementation to the achievement of the process. All of these systems need to be explained and applied in legal form with XYZ.

\section{Discussion Description of Formula ALAMIN}

Explanation of formulas is needed to be a guideline or procedure for applying a formula. The explanation for the ALAMIN formula is directly related to the procedure for applying ALAMIN formulas in everyday life. Explanation of the ALAMIN formula becomes one concrete explanation in the aspect of implementation. XYZ communication is not only known as a term in the science of communication, but based on the ALAMIN formula, XYZ communication becomes a complete application in the implementation process to become a

\footnotetext{
${ }^{1}$ Muhammad Aminullah, Theory of Alamin: A Formation of Universal Communication Formula, Budapest International Research and Critics Institute-Journal (BIRCI-Journal) Volume 1 No. 2, June 2018, (www.bircujournal.com/index.php/birci) p. 167

${ }^{2}$ Muhammad Aminullah, Komunikasi Alamtologi: Alamin, Jilid I, (Kuala Lumpur: Nature Pattern Resources Sdn. Bhd, Cet. 1, 2018), p. 372
} 
harmonious relationship that can be applied directly in his life. Therefore, ALAMIN is an alternative communication science that can explain XYZ's relationship in life, so that it becomes a harmonious relationship.

In this case, the explanation of the use of ALAMIN formulas is a constant guide to carrying out XYZ communication by using the appropriate interaction process with the equilibrium values for all elements in space $\mathrm{Z}$. As explained by Masa Bayu, the XYZ Formula becomes the most basic principle in the life process. ${ }^{3}$ The form of explanation of ALAMIN formula to be applied in life, can be understood based on the form that occurs in the basic process before producing a form of explanation of the formula. This means that before getting an explanation of the formula, it requires a form of the process of explaining the formula. The form of the formula explanation process can be understood based on Figure 4.24 below.

\begin{tabular}{|c|c|}
\hline FORMULA & INFORMATION \\
\hline$X \frac{A^{h}}{E^{h}} P_{1-7}+Z \frac{m}{t}=X \frac{A^{h} P_{1-7}}{E^{h} P_{1-7}}+Z \frac{m}{t}$ & $\begin{array}{l}\mathrm{X}=\text { Executor } \\
\mathrm{Z}=\text { Media \& Reference For } \mathrm{X} \\
\mathrm{Ah}=\text { Legal Accuracy } \\
\text { Eh }=\text { Law Envoy } \\
-\quad=\text { Refuse (Not Accept) } \\
\mathrm{P}_{1-7}=\text { Implementation Process at Ranking 1-7 } \\
\mathrm{m}=\text { Period } \\
\mathrm{t}=\text { Power }\end{array}$ \\
\hline
\end{tabular}

Figure. 2: Process Form Formula Explanation in ALAMIN Formula

Based on the explanation in Figure 2, it can be understood that the form of the process of explanation of the ALAMIN formula can be formed by means of $\mathrm{X}$ can use the right choice in the process of implementing communication to use $\mathrm{Z}$ as the media. Is there $\mathrm{X}$ using legally or lawfully in joining $\mathrm{Z}$ to make the media in the process of explaining the formation of formulas. As for the formula explanation process to be implemented in its assignment, $\mathrm{X}$ has a ranking process that must be determined by $\mathrm{X}$ in the implementation of the assignment based on both $\mathrm{Ah}$ and Eh. This is very much related to the $\mathrm{X}$ implementation process in explaining the use of media $\mathrm{Z}$ appropriately with the need for $\mathrm{X}$ to produce harmonious communication values in XYZ relationships.

The form of explanation in the use of ALAMIN formula rather than the formation of the formula, can be understood based on the formula formula as follows.

\footnotetext{
${ }^{3}$ Masa Bayu, ALAMTOLOGI: Formula XYZ, jld. 1, (Kuala Lumpur: Nature Pattern Resources Sdn. Bhd, 2018), p. 56
} 


\begin{tabular}{|c|c|}
\hline FORMULA & INFORMATION \\
\hline $\begin{array}{l}X\left(A^{h} P_{1-7}\right)+Z \frac{m}{t}=g H p \\
X\left(E^{h} P_{1-7}\right)+Z \frac{m}{t}=g C p\end{array}$ & $\begin{array}{l}\mathrm{X}=\text { Executor } \\
\mathrm{Z}=\text { Media \& Reference For } \mathrm{X} \\
\text { Ah = Legal Accuracy } \\
\text { Eh = Law Envoy } \\
\mathrm{P}_{1-7}=\text { Implementation Process At Rank 1-7 } \\
\mathrm{m}=\text { Period } \\
\mathrm{t}=\text { Power } \\
\mathrm{gHp}=\text { Generic Harmonic Pattern } \\
\mathrm{gCp}=\text { Generic Corrupted Pattern }\end{array}$ \\
\hline
\end{tabular}

Figure. 3: Formula Formula Explanation of NATURE Formula ${ }^{4}$

Based on the formula formula, it can be understood that the explanation of the ALAMIN formula can be done by using the results of the achievement rather than the process in explaining the formula. Therefore, if the explanation of the formula rather than the implementation of the process on $\mathrm{X}$ based on $\mathrm{X}\left(\mathrm{A}^{\mathrm{h}} \mathrm{P}_{1-7}\right)$ joins in the form of prosperity $\mathrm{Z}$ which has mass and energy content, it can produce an explanation of the ALAMIN formula in a formula that gives harmony to all. But if the explanation of the formula rather than the implementation of the process on $\mathrm{X}$ based on $\mathrm{X}\left(\mathrm{E}^{\mathrm{h}} \mathrm{P}_{1-7}\right)$ joins in the form of destroying the element $\mathrm{Z}$ which has a mass and energy content, it can produce an explanation of the ALAMIN formula in the form of a formula that gives all values of lameness.

The explanation of the ALAMIN formula can be understood based on four main functions rather than the explanation process of the formula, among others, namely; explanatory functions, process planning functions, functions of achieving results of reality and functions of certainty of results. These four functions really need to be the basic principle in explaining the ALAMIN formula. The explanation of the four functions of the explanation of the ALAMIN formula can be understood based on the following explanation.

\section{a. Function Explain}

The function explained is the most important function to be owned by each formation of a formula. This is due to the formation of formulas not only for a statement, but need an explanation that can be applied in life. Therefore, so also in the formation of ALAMIN formulas, where the formation of formulas in the theory can explain the form of application of the theory in the process of implementing communication that can connect $\mathrm{XYZ}$ in harmony.

The insights that can be developed in ALAMIN based on explanations rather than the basis of formulas, namely this theory can be applied scientifically and systematically in everyday life. This is due to the ALAMIN formula explaining that communication is formed from an interaction that can connect one to another on the basis of needs. Based on this explanation it can be understood that every need for something must be done an interaction to get something that is needed. The form of application in the explanation of ALAMIN formula

\footnotetext{
${ }^{4}$ Muhammad Aminullah, Komunikasi Alamtologi: Alamin, Jilid I, (Kuala Lumpur: Nature Pattern Resources Sdn. Bhd, Cet. 1, 2018), p. 416
} 
needs to be understood that the process of implementing interactions must require a balance value in the use of media to get something that is needed right at the level and position.

The explanation formula for ALAMIN formula in the function of explaining the theory formula is balanced in the XYZ relationship, can be understood based on Figure 4.26 below.

$$
A^{h} \frac{X P+1-7}{X P-1-7}+Z \frac{m}{t}=g H p
$$

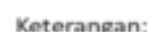

Information:

$\mathrm{X}$ : Executor

Z: Media \& Reference For X

Ah: Accurate Law

$\mathrm{P}+1$-7: Passive Implementation Process At

Ranks 1-7

P-1-7: Active Process Implementation at

Ranks 1-7

M: Masa

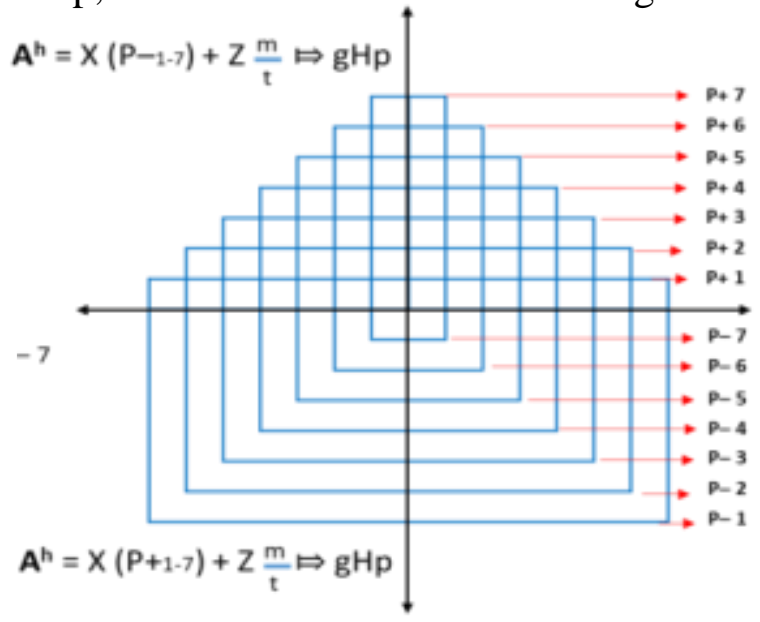

T: Power

Figure. 4: Formulas for Explaining the NATURAL Formula for the Application of XYZ

\section{Communication $^{5}$}

Based on this formula, it can be understood that the explanation of the ALAMIN formula can function to explain the form of XYZ communication applications that can be used based on actual implementation. ALAMIN formula can provide ideas and guidance on how to implement communication that can connect XYZ in the form of harmony. Based on Figure 4.26, it can be understood that communication applications rather than explanations of this formula can be done by means of $\mathrm{X}$ being consistent in the form of legal agreement to communicate in a gradual manner in using $\mathrm{Z}$ media appropriately. This means that if $\mathrm{X}$ carries out communication at number one (P1) both in the passive position and in the active position, then the use of $\mathrm{Z}$ media must also use the right element with that rating, that is, $\mathrm{Z}$ at number one (P1) too. The explanation of the use of formulas based on the tattoo image that serves to explain how to use formulas in XYZ communication applications that harmony can be understood based on the following explanation.

$$
\begin{aligned}
& \text { If } \mathrm{Ah}=\mathrm{X}(\mathrm{P}+1) \text {, then }+\mathrm{Z}(\mathrm{P}-1) \mathrm{m} / \mathrm{t} \text { to reach } \Leftrightarrow \mathrm{gHp} \\
& \text { If } \mathrm{Ah}=\mathrm{X}(\mathrm{P}+2) \text {, then }+\mathrm{Z}(\mathrm{P}-2) \mathrm{m} / \mathrm{t} \text { to reach } \Leftrightarrow \mathrm{gHp} \\
& \text { If } \mathrm{Ah}=\mathrm{X}(\mathrm{P}+3) \text {, then }+\mathrm{Z}(\mathrm{P}-3) \mathrm{m} / \mathrm{t} \text { to reach } \Leftrightarrow \mathrm{gHp} \\
& \text { If } \mathrm{Ah}=\mathrm{X}(\mathrm{P}+4) \text {, then }+\mathrm{Z}(\mathrm{P}-4) \mathrm{m} / \mathrm{t} \text { to reach } \Leftrightarrow \mathrm{gHp} \\
& \text { If } \mathrm{Ah}=\mathrm{X}(\mathrm{P}+5) \text {, then }+\mathrm{Z}(\mathrm{P}-5) \mathrm{m} / \mathrm{t} \text { to reach } \Leftrightarrow \mathrm{gHp} \\
& \text { If } \mathrm{Ah}=\mathrm{X}(\mathrm{P}+6) \text {, then }+\mathrm{Z}(\mathrm{P}-6) \mathrm{m} / \mathrm{t} \text { to reach } \Leftrightarrow \mathrm{gHp} \\
& \text { If } \mathrm{Ah}=\mathrm{X}(\mathrm{P}+7) \text {, then }+\mathrm{Z}(\mathrm{P}-7) \mathrm{m} / \mathrm{t} \text { to reach } \Leftrightarrow \mathrm{gHp}
\end{aligned}
$$

Figure. 5: Function Explaining ALAMIN Formula in Passive $\mathrm{X}$ and $\mathrm{Z}$ Active Form

\footnotetext{
${ }^{5}$ Muhammad Aminullah, Komunikasi Alamtologi: Alamin, Jilid I, (Kuala Lumpur: Nature Pattern Resources Sdn. Bhd, Cet. 1, 2018), p. 419
} 
This process explains that the explanation of ALAMIN formula can be applied in life by $\mathrm{X}$ in the form of $\mathrm{X}$ in the active position, while the use of $\mathrm{Z}$ media in the passive form. This process is to reach a balance point in implementing XYZ communication. While the next explanation is if $\mathrm{X}$

is in the passive position, then the use of $\mathrm{Z}$ media is in the active form. The process of passively active pairs in the process of implementing communication is a goal in the function of explaining the ALAMIN formula. The second position is in the process of explaining the formula as explained below.

$$
\begin{aligned}
& \text { If } A h=X(P-1) \text {, then }+Z(P+1) \mathrm{m} / t \text { to reach } \Leftrightarrow g H p \\
& \text { If } A h=X(P-2) \text {, then }+Z(P+2) \mathrm{m} / \mathrm{t} \text { to reach } \Leftrightarrow \mathrm{gHp} \\
& \text { If } A h=X(P-3) \text {, then }+Z(P+3) \mathrm{m} / \mathrm{t} \text { to reach } \Leftrightarrow \mathrm{gHp} \\
& \text { If } \mathrm{Ah}=\mathrm{X}(\mathrm{P}-4) \text {, then }+\mathrm{Z}(\mathrm{P}+4) \mathrm{m} / \mathrm{t} \text { to reach } \Leftrightarrow \mathrm{gHp} \\
& \text { If } \mathrm{Ah}=\mathrm{X}(\mathrm{P}-5) \text {, then }+\mathrm{Z}(\mathrm{P}+5) \mathrm{m} / \mathrm{t} \text { to reach } \Leftrightarrow \mathrm{gHp} \\
& \text { If } \mathrm{Ah}=\mathrm{X}(\mathrm{P}-6) \text {, then }+\mathrm{Z}(\mathrm{P}+6) \mathrm{m} / \mathrm{t} \text { to reach } \Leftrightarrow \mathrm{gHp} \\
& \text { If } \mathrm{Ah}=\mathrm{X}(\mathrm{P}-7) \text {, then }+\mathrm{Z}(\mathrm{P}+7) \mathrm{m} / \mathrm{t} \text { to reach } \Leftrightarrow \mathrm{gHp}
\end{aligned}
$$

Figure. 6: Function Explaining NATURAL Formula in Active $\mathrm{X}$ and $\mathrm{Z}$ Passive Forms

The two forms of communication implementation process based on the ALAMIN formula explanation function can be understood, which is based on the movement of processes in both forms, becoming a way of understanding the movement of the XYZ communication process appropriately. However, in the two forms of passive movement and active movement, it has a balanced point which has a link between the passive process and the active process in all rankings of the movement process in the communication, which is found at $\mathrm{P}+4$ and $\mathrm{P}-4$. Evidence of the balance in the explanation of ALAMIN can be understood based on Figure 7 below.

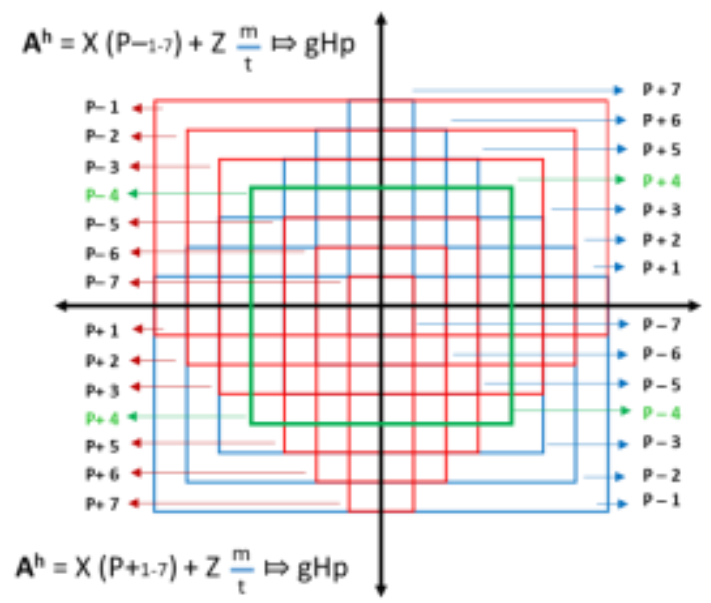

Figure. 7: Forms of Balanced Points in P4 in Functions Explaining in ALAMIN Formula

Based on the explanation of the balance points found in Figure 7, it can be understood that this balance point is seen in the process of ranking the fourth $\mathrm{P} 4$, in the form of $\mathrm{X} \mathrm{P}+$ and $\mathrm{Z} \mathrm{P}$ - with $\mathrm{X} \mathrm{P} \mathrm{-} \mathrm{and} \mathrm{Z} \mathrm{P} \mathrm{+.} \mathrm{The} \mathrm{balance} \mathrm{point} \mathrm{at} \mathrm{number} \mathrm{four} \mathrm{shows} \mathrm{the} \mathrm{point} \mathrm{that} \mathrm{can}$ connect the communication application process in the explanation of the NATURAL formula based on the relationship of passive and active processes. Point P4 is referred to as a balanced point, does not mean the point of perfection of the process. But this point becomes the right 
connecting point in passive and active relationships and active and passive relationships, to make the process perfect from rank one (P1) to seventh (P7).

As for how to explain the ALAMIN formula that is legally accurate in the implementation of $\mathrm{XYZ}$ communication, it can be understood that every action taken by $\mathrm{X}$ in using $\mathrm{Z}$ must understand the value of prosperity possessed by $\mathrm{Z}$ element, this concept is carried out as a function of explaining the use of $Z$ element balanced between the relationship $X$ with $Z$. Like $X$ requires wood to make a house. In the use of wood, when $X$ cuts wood, $X$ must understand the conditions around it, so that the wood cutting done by $\mathrm{X}$ does not damage other $\mathrm{Z}$ elements around it. Besides this, $\mathrm{X}$ must also understand the risks that exist when the wood is cut. With this concept, protected forests can be maintained and maintained from all the risks.

\section{b. Process Planning Function Not Predicting Process}

The planning function is one of the functions that is very important in explaining the use of ALAMIN formulas. This shows that every XYZ communication formed in the ALAMIN formula has one appropriate plan in each assignment implementation process. Process planning is very important to be the initial foundation for the formation of formulas, so that the formula that is produced rather than the right planning can be directed based on the provisions of the plan. The process planning function in explaining the ALAMIN formula to realize the implementation of XYZ communication can be arranged in a good management manner. The result is XYZ communication can be formed systematically that can be proven based on scientific applications.

The process planning function to be able to explain the formation of ALAMIN formulas can be understood based on Figure 8 below.

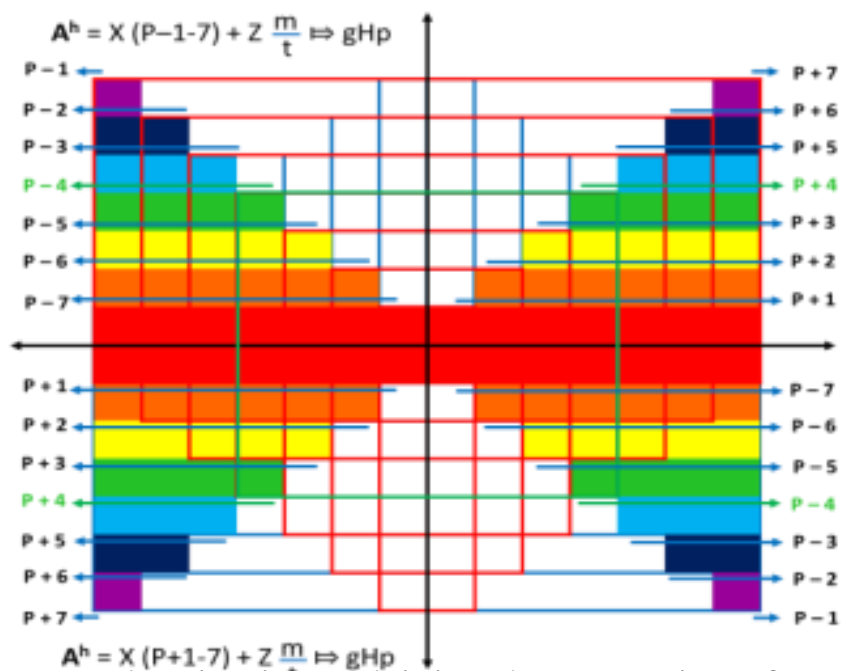

Figure. 8: Forms of Process Planning in Explaining the Formation of a NATURAL Formula

Based on Figure 8, it can be understood that every planning in the implementation of the process must have the right planning in explaining the formation of XYZ communication. The figure illustrates the process of planning steps needed to explain the ALAMIN formula correctly to form XYZ communications that are legally legal. Therefore, each stage of the implementation has their respective roles that must be fulfilled in each ranking process. This 
proves that the second rank planning $(\mathrm{P} 2)$ can be done after completing the process planning in the first rank $(\mathrm{P} 1)$.

The explanation of the ranking in the process of being able to explain the form of ALAMIN formula can be understood based on Figure 9 below.

\begin{tabular}{|c|c|}
\hline \multicolumn{2}{|c|}{ Planning Function $\square$ Merge Form) } \\
\hline P1 & $=\mathbf{P 1}$ \\
\hline $\mathbf{P 2}$ & $=\mathbf{P} 1+\mathbf{P 2}$ \\
\hline P3 & $=\mathbf{P} 1+\mathbf{P} 2+\mathbf{P} 3$ \\
\hline P4 & $=\mathbf{P 1}+\mathbf{P 2}+\mathbf{P 3}+\mathbf{P 4}$ \\
\hline P5 & $=\mathrm{P} 1+\mathrm{P} 2+\mathrm{P} 3+\mathrm{P} 4+\mathrm{P} 5$ \\
\hline P6 & $=\mathrm{P} 1+\mathrm{P} 2+\mathrm{P} 3+\mathrm{P} 4+\mathrm{P} 5+\mathrm{P} 6$ \\
\hline P7 & $=\mathrm{P} 1+\mathrm{P} 2+\mathrm{P} 3+\mathrm{P} 4+\mathrm{P} 5+\mathrm{P} 6+\mathrm{P} 7$ \\
\hline
\end{tabular}

\begin{tabular}{|c|c|}
\hline \multicolumn{2}{|c|}{ Planning Function $\square$ Flattened Form) } \\
\hline & 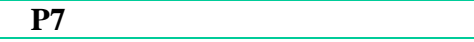 \\
\hline P7 & $=\mathbf{P 6}-\mathrm{P} 1$ \\
\hline P6 & $=\mathbf{P 5}-\mathrm{P1}-\mathrm{P1}$ \\
\hline P5 & $=\mathrm{P} 4-\mathrm{P} 1-\mathrm{P} 1-\mathrm{P} 1$ \\
\hline $\mathbf{P 4}$ & $=\mathbf{P 3}-\mathbf{P 1}-\mathbf{P 1}-\mathbf{P 1}-\mathbf{P} 1$ \\
\hline P3 & $=\mathbf{P} 2-\mathbf{P} 1-\mathbf{P 1}-\mathbf{P} 1-\mathbf{P} 1-\mathbf{P} 1$ \\
\hline $\mathbf{P 2}$ & $=\mathbf{P} 1-\mathbf{P} 1-\mathbf{P} 1-\mathbf{P} 1-\mathbf{P} 1-\mathbf{P} 1-\mathbf{P} 1$ \\
\hline & 彗拜拜手 \\
\hline P1 & $=\mathbf{P 7}-\mathrm{P} 6-\mathrm{P} 5-\mathrm{P} 4-\mathrm{P3}-\mathrm{P} 2-\mathrm{P} 1$ \\
\hline
\end{tabular}

Figure. 9: Forms of Use of Planning Ranking in Explaining NATURAL Formula

Based on Figure 9, it can be understood that a very important process planning function was formed precisely in the explanation of the use of the ALAMIN formula to be able to achieve XYZ communication that is right on target. This shows that the P1 ranking plan is very decisive for the formation of an explanation of the ALAMIN formula at rank P2, P3, P4, P5, P6 and P7. The P4 ranking plan is crucial for the formation of an explanation of the ALAMIN formula in the ranks P5, P6 and P7. The P5 ranking plan is very decisive for the formation of an explanation of the ALAMIN formula in the ranks P6 and P7. The last one is the P6 rating plan which is crucial for the formation of an explanation of the ALAMIN formula in the P7 rating. Therefore, the formation of the ALAMIN formula in explaining the form of $\mathrm{XYZ}$ communication is closely related to the ranking of the appropriate process planning based on each rank to produce a complete ranking, which is ranked seven. The way to estimate it is to follow the aid system in mathematical ALAMTOLOGY. ${ }^{6}$

The four stages are the accuracy of planning, preparation of planning tools, the availability of planning tools and the willingness of the implementer to carry out the implementation process. The first stage is the accuracy of planning. The accuracy of planning, namely $\mathrm{X}$ must be able to determine each implementation process by regulating the accuracy of the planning process. The accuracy of this plan can be established in the process before carrying out the implementation and when carrying out the tasks and end rather than carrying out the implementation. This means that every implementation of the assignment already has a complete concept of planning accuracy.

The second stage is preparation of tools to carry out the planning process. Tool preparation is one of the most important elements in each planning implementation. Preparation of tools is needed so that each assignment has the right tools to be used in carrying out the assignment. As for the implementation of $\mathrm{XYZ}$ communication, preparation of tools becomes an important element which acts as a media element needed for proper communication. Thus the accuracy of the preparation of tools provided for use in the

\footnotetext{
${ }^{6}$ Masa Bayudan Fatimah, Matematik ALAMTOLOGI: Hisal Bahagian Aidil, Jilid I, (Kuala Lumpur: Nature Pattern Resources Sdn. Bhd, Cet. 1, 2017), p. 11
} 
implementation of communication can determine the achievement of the communication appropriately.

The preparation for using the tool is the right plan in implementing $\mathrm{XYZ}$ communication as must be formed in the explanation of the ALAMIN formula. Tool preparation is the most important element in the use of communication media. This shows that the media used have complete preparation before using the media to carry out the interaction process in forming harmonious communication in the XYZ relationship. Preparation of tools can be done in a real form, such as the preparation of the right glass for use in the process of drinking water appropriately. Likewise, it is like preparing the right dishes to be used in the process of eating properly. Besides that, it is also like preparing a cloth towel $\square$ tuala) to dry the water on the body after bathing. So based on these examples, it can be understood that before the execution of the assignment, it was very necessary to prepare the tool as the right medium to produce the perfection of the process in each assignment.

The third stage is the willingness of tools to carry out the planning process in XYZ communication. The availability of tools is a process of the form of inventory after the preparation of tools that will be used as XYZ communication media. The difference is the preparation of tools with the availability of tools that are found in the implementation of the process. Tool preparation is the process of finding the right tool to use as an XYZ communication medium. Whereas the availability of tools is every tool that has been prepared so that it is willing to be used appropriately. This means that the prepared tools have been checked for all the completeness of all the shortcomings for the readiness to use the tool that will be used in XYZ communication. By

While the fourth stage is the last step in the planning function of the process of explaining the use of ALAMIN formulas in the implementation of XYZ communication. The fourth stage is the implementer's willingness. Implementation willingness is one of the most important processes than the previous three stages of the process. This proves that every media that is available properly, it is necessary to have $\mathrm{X}$ ready to use the media.

\section{c. Function of Achieving Realistic Results Not Perception Results}

The function of achieving the results of reality in the explanation of the ALAMIN formula is a must in each formula formation must have the achievement of results that can be explained in reality. Reality explanation is the achievement of results that can be proven in a scientific, systematic and universal form. This proves that the formulas produced have explanations that can be applied in the form of tangible achievements precisely. This means that anyone who uses the same concept with the same implementation, then the achievement of results is the same.

The formula for achieving the results of reality based on Figure 8 on the explanation of the formation of ALAMIN formulas can be understood as follows. 


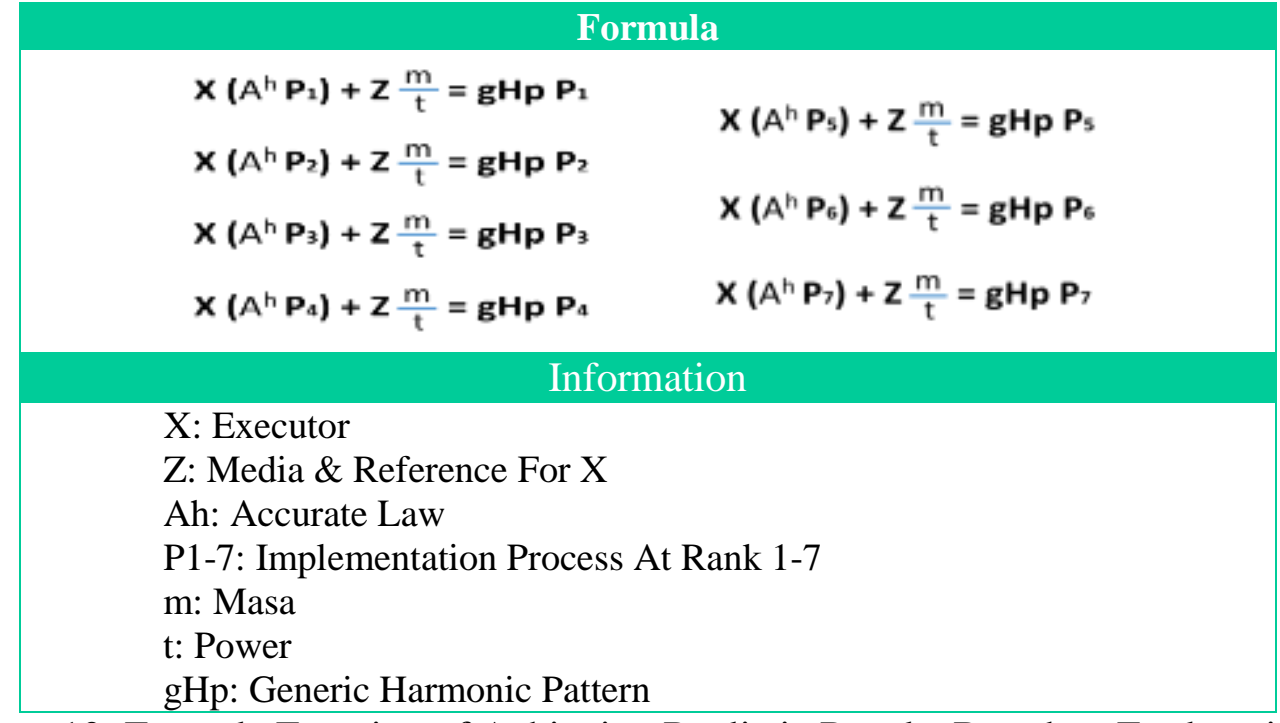

Figure. 10: Formula Function of Achieving Realistic Results Based on Explanation of NATURAL Formula

Based on this formula it can be understood that the achievement of reality results can be found based on the exact certainty of the process in reality as well. This means that the accuracy of the process is based on clear facts, so it certainly results in clear facts. This concept proves that the certainty of results is based on the certainty of the process. So if the process is uncertain, it will produce predictive values. Thus it can be understood that the results of predictions found based on the implementation process starts from something uncertain. Therefore, the ALAMIN formula can explain XYZ communication that is formed to achieve definite results, not realistic results. As $X$ removes garbage in the space provided, then the $\mathrm{X}$ assignment can achieve clean reality results in space $\mathrm{Z}$.

Achieving the results of the reality formed in the explanation of the ALAMIN formula is an implementation rather than the results of planning. This means that if in planning as preparation and procurement of tools to carry out the process, then the achievement function is the implementation produced rather than the plan. As for planning is called an effort, the function of achievement is the stage in the business ranking. The form of achievement of results based on the implementation process of assignments in rank one (P1) in reality can be understood based on the following formula.

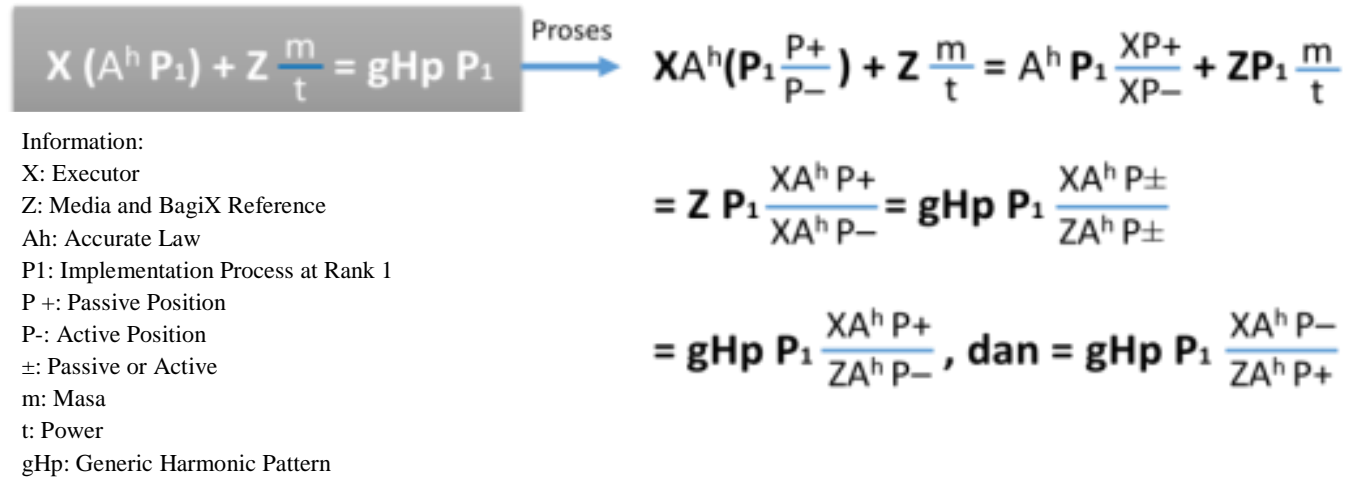

Figure. 11: Function of Achieving Rank 1 Results in the Form of Explanation of ALAMIN Formula 
Based on the formula described in Figure 11, it can be understood that the achievement of realistic results is in the accuracy of process planning and the accuracy of the process. Explanation on the formula can be understood that the achievement of gHpP1 XAhP + / ZAhP-, and gHpP1 XAhP- / ZAhP +. The form of achievement of the assignment on the perfection of rank, namely the implementation of $\mathrm{XYZ}$ communication carried out by $\mathrm{X}$ in using $\mathrm{Z}$ is ranked seventh (P7), as can be understood based on the following formula.

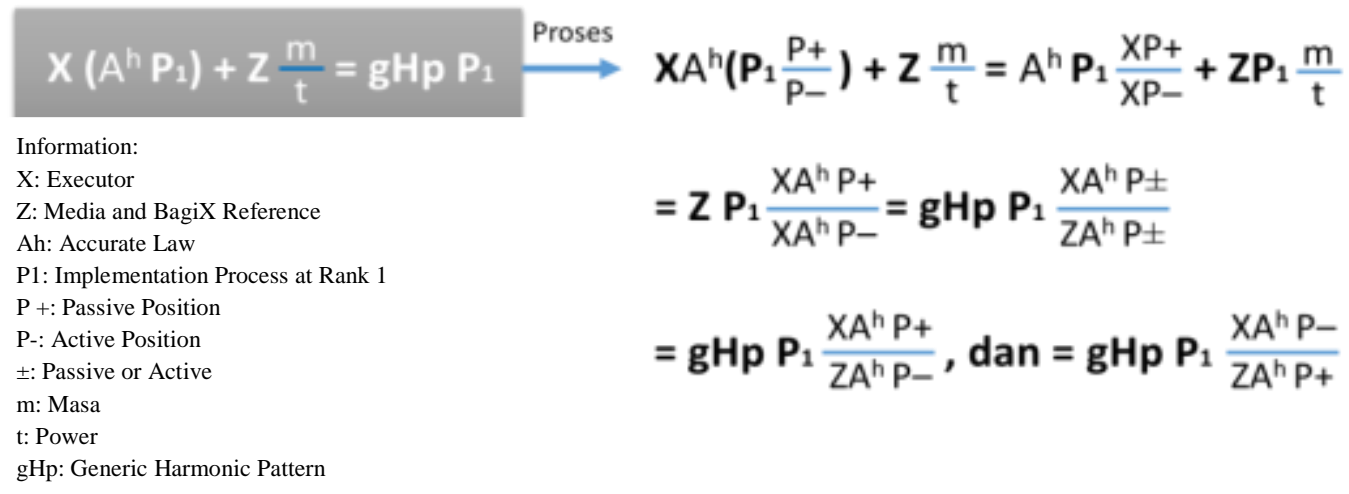

Figure. 12: Function of Achieving the Results of Reality Ranking 7 in the Form of Explanation of the NATURAL Formula

Based on the explanation on the ranking formula, it can be understood that the achievement of the seventh ranking reality results is formed from the planning process in harmonizing $\mathrm{XYZ}$ communication, namely gHpP7 XAhP + / ZAhP-, and gHpP7 XAhP- / $\mathrm{ZAhP}+$. The achievement of the seventh process is the result of a process perfection in each ranking of the assignment. Therefore, the achievement found is the result of the implementation of a process based on planning carried out by $\mathrm{X}$ in the use of $\mathrm{Z}$ elements as media.

\section{d. The Function of Certainty of Results Is Not a Prediction of Results}

The results of the certainty function are goals that must be found in the formation of an explanation of the ALAMIN formula. Certainty of results is a target that must be found by $\mathrm{X}$ at each implementation of the interaction process in forming harmony of $\mathrm{XYZ}$ communication that is awakened based on the ALAMIN formula. Certainty of results is found rather than the accuracy in the formation of processes. But if there is no accuracy in forming a process, what is found is the prediction of results. This is because the implementation of a process that is not of accuracy is an implementation that is built on a perception. Implementation that is built on perception will produce a prediction, not a certainty.

Based on this concept, the ALAMIN formula in explaining XYZ communication, must be formed based on the certainty of the process, the goal is to achieve certainty of results. Therefore XYZ communication which is formed based on this formula, becomes a communication that has certainty of results in every communication implementation that is awakened by $\mathrm{X}$. Thus, the implementation of $\mathrm{X}$ in using element $\mathrm{Z}$ as a media becomes a definite implementation in getting the right results the main purpose of XYZ communication.

Achieving the certainty of the results following the achievements produced based on the certainty of the process carried out by $\mathrm{X}$ in carrying out the task as the executor of $\mathrm{XYZ}$ 
communication. To get certainty of results based on estimates made on the certainty of the process, it can be found based on the process movements that apply in the XYZ relationship. $\mathrm{X}$ has a role in regulating process movements in $\mathrm{XYZ}$ communication based on the certainty of the process to find certainty of results. Therefore, to understand the certainty of results in the first rank rather than the certainty of the process in the first movement until the seventh movement, it can be understood based on Figure 13 below.

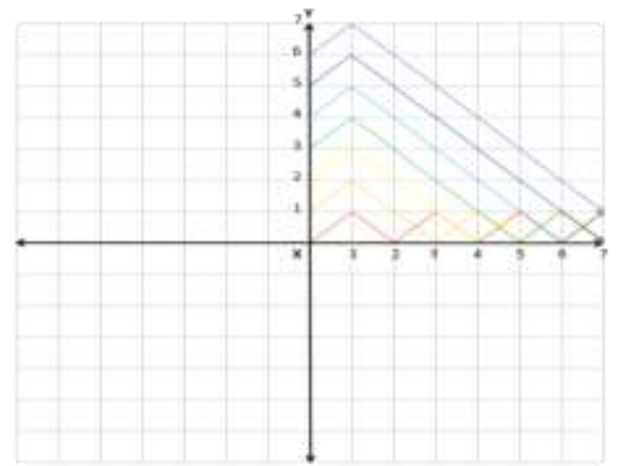

Figure. 13: Forms of Certainty of the Movement Process (P1-7) To Achieve Certainty of Results at Rank One in XYZ Communication Based on ALAMIN Formula

The process will continue to develop until the process of perfection is in the seventh rank. The way to understand the certainty of results in the seventh rank rather than the certainty of the process in the first movement until the seventh movement in explaining ALAMIN formula, can be understood based on Figure 14 below.

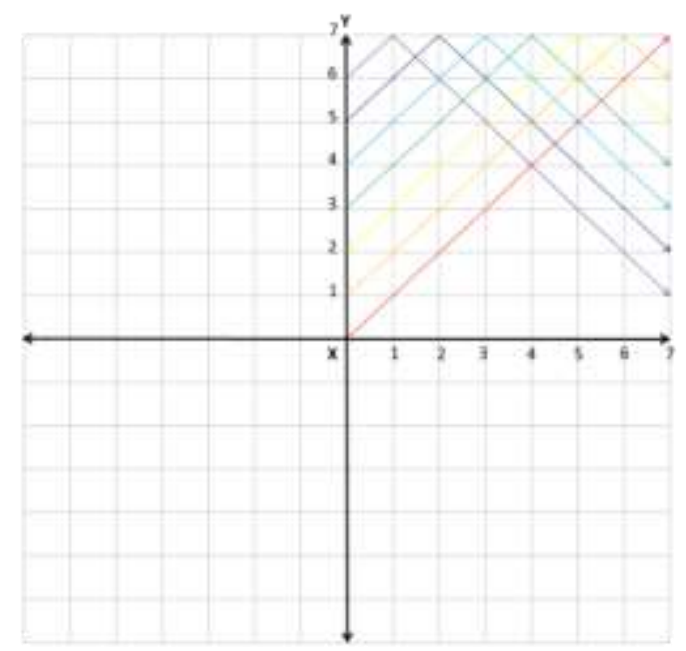

Figure. 14: Forms of Certainty of the Movement Process (P1-7) To Achieve Certainty of

Results at Rank Seven in XYZ Communication Based on ALAMIN Formula

Based on Figure 14, it can be understood that the last process certainty movement to achieve certainty of results in XYZ communication on movement (P1-7) is ranked seven based on the ALAMIN formula, which can be found based on the movement possessed by $\mathrm{X}$ as the communication implementer. As for the first movement at number seven, namely $\mathrm{X}=$ 0 and $\mathrm{Y}=0$ as the beginning of the certainty of the process, but in this process there is no 
implementation of the process. While the results of process certainty are $(X=7, Y=7)$. No process implementation does not mean achieving certainty of results rather than certainty that the process does not have a process implementation. However, the process of this movement is a process perfection rather than the first movement of all rankings, which starts from rank one to rank seven.

The achievement of the process certainty function is a form of XYZ communication that can be done in fact on the implementation of $\mathrm{X}$ itself. This proves that $\mathrm{XYZ}$ communication has a definite formation process that begins with the certainty of the process, then the certainty of the implementation of the process and achieving certainty of process results. With this system, XYZ communication is formed in the explanation of the ALAMIN formula, which is a communication that is formed not in a perceptual process so as to achieve predictions of results. Therefore, XYZ communication is formed based on certainty, not a prediction achievement.

\section{Conclusion}

The right communication is communication carried out by legal means. Legal accuracy is the value of accuracy possessed by the XYZ element in the communication process. The accuracy of legal agreement is the result of a decision that is used as the principle of the implementation of the process by $\mathrm{X}$. $\mathrm{X}$ as an executor based on decisions taken without any interference from the parties. Whereas $\mathrm{Z}$ is a media that is used as a communication tool by $X$. So the position of $Z$ as a media remains in the value of getting along with the law. Therefore $\mathrm{Z}$ has no changes. Whereas $\mathrm{Z}$ changes are caused by the results of $X$ 's decision, not rather than self-change $\mathrm{Z}$. whereas $\mathrm{Y}$ is the creator to foster all existing facilities in space $Z$ and creator $X$, so that all facilities that form $Z$ space become the right media to be used by $X$ in doing harmony communication. Thus harmony communication is the result of the implementation of $\mathrm{X}$ in making relations with others based on legal value. The process of harmonious communication must be right, which starts from process planning, process implementation to the achievement of the process. The way to implement the right communication process in achieving harmony values for all elements related to humans, namely communication must be carried out with four stages that are right on the basis of legal agreement. The four stages are the accuracy of planning, preparation of planning tools, availability of planning tools and willingness of the implementer to carry out the implementation process. Communication will not produce harmonious value if it is based on the concept of predicting processes, process perceptions, and results of output. This is because communication in the form does not have the right practical value to ensure legal legality or lawlessness. Thus, proper communication is able to produce certainty based on the certainty of the process results. However, if communication is based on perceptions of the process, then it certainly produces predictions of results. This is what is called harmony communication. Thus it can be concluded that the best communication is the right communication with what is needed. Then the right communication is to say what is done and do not say what is not done. This is the meaning of legal communication in its nature. 


\section{References}

Masa Bayudan Fatimah, Matematik ALAMTOLOGI: Hisal Bahagian Aidil, Jilid I, Kuala Lumpur: Nature Pattern Resources Sdn. Bhd, Cet. 1, 2017

Masa Bayu, ALAMTOLOGI: Formula XYZ, jld. 1, Kuala Lumpur: Nature Pattern Resources Sdn. Bhd, 2018

Muhammad Aminullah, Theory of Alamin: A Formation of Universal Communication Formula, Budapest International Research and Critics Institute-Journal, BIRCI-Journal, Volume 1 No. 2, June 2018, www.bircu-journal.com/index.php/birci

Muhammad Aminullah, Komunikasi Alamtologi: Alamin, Jilid I, Kuala Lumpur: Nature Pattern Resources Sdn. Bhd, Cet. 1, 2018 